\title{
Quantitative microfocal radiography accurately detects joint changes in rheumatoid arthritis
}

\author{
J C BUCKLAND-WRIGHT, I CARMICHAEL, AND S R WALKER
}

From the Macroradiographic Research Unit, Department of Anatomy, University Medical \& Dental Schools of Guy's and St Thomas's Hospitals, Guy's Campus, London SE1 9RT

SUMMARY Microfocal radiography, producing $\times 5$ magnified images of the wrist and hands with a high spacial resolution $(25 \mu \mathrm{m})$ in the film, permitted direct measurement of erosion area and joint space width in patients with rheumatoid arthritis. The magnitude of errors relating to direct measurement, repositioning the wrist and hand on successive $x$ ray visits, repeated identification of erosions and their area calculation were assessed. The coefficients of variation for length and area measurements were $3.7 \%$ and $13 \%$ respectively, while the change in joint space width and erosion area in five patients over 18 months had average coefficients of variation of $12.7 \%$ and $42.0 \%$ respectively. The combined errors correspond approximately to the fifth percentile level for the total changes in size of these $x$ ray features. The remaining alterations were due to the disease, which was markedly greater than that attributable to errors of measurement.

The accuracy of conventional $x$ ray machines has been evaluated in terms of the extent to which lesions produced either as a result of pathological conditions $^{1-3}$ or experimentally $y^{4-6}$ were recorded. Frequently the lesions were either not detected or recorded indistinctly on the radiographs. When Becks and Grimm $^{7}$ tried to establish a correspondence between the histological and the radiographic appearance of morphological changes in bone they found that the resolution in the film was not good enough to record detailed alterations. With the development of the microfocal $x$ ray units ${ }^{8}$ a variety of methods has been used to describe the fine bone detail recorded in the magnification radiographs. ${ }^{9-11}$ The correspondence between the detailed organisation of bone, its histology, and its $x$ ray appearance was established, ${ }^{10} 11$ permitting the quantitative evaluation of detailed structure. ${ }^{12}$ A study of the radiological progression of erosions and juxtaarticular osteoporosis in the knee joints of guinea pigs with experimentally induced inflammatory arthritis has been possible. ${ }^{13}$

Microfocal projection radiography ${ }^{14-16}$ has led to earlier identification of erosions in the wrist and

Accepted for publication 11 September 1985.

Correspondence to $\mathrm{Dr} \mathrm{J}$ C Buckland-Wright, Department of Anatomy, Guy's Hospital Medical \& Dental Schools, London SE1 9RT. hand of patients with rheumatoid arthritis ${ }^{15} 16$ and improved the assessment of disease progression. ${ }^{17}$ In common with previous applications of microfocal radiography, ${ }^{10-14}$ direct measurement of the size of lesions and their changes offers a far more precise method of determining radiographic progression than is available with standard $x$ ray procedures.

This paper is the first of a series presenting the results of the quantitative evaluation of radiographic progression in patients with rheumatoid arthritis (RA). It describes the accuracy of the method of measurement currently being applied to the macroradiographs of these patients. It identifies and quantifies the errors associated with direct measurement of length and the area of lesions of different sizes, the distortion of length and area measurements resulting from repositioning of the wrist and hand on successive $x$ ray visits, and the accuracy in the identification and measurement of erosions. A comparison of the errors with the magnitude of changes found in five RA patients over 18 months has also been made.

\section{Patients and methods}

Macroradiographs were drawn at random from those of a group of 37 RA patients of mixed severity who were being followed radiographically with $x$ ray visits at six monthly intervals. 
The microfocal projection $x$ ray unit ${ }^{14}$ and the preparation of the stereopair magnification radiographs ( $\times 5$ magnification) of the wrist and hands of patients ${ }^{15} 17$ have been described previously. For three dimensional assessment of the radiographic features the stereopair macroradiographs were set up under a stereoscope. ${ }^{15}$ Both radiographic carriages were illuminated, the right one comprising the digitiser tablet. All measurements were made with a Reichert-Jung MOP 1 image analyser linked to a digitiser tablet. In turn the MOP was connected to a CBM 4032 microcomputer system. A cross wire cursor was used to outline the structures in the radiograph overlying the digitiser.

Tests on direct measurement accuracy for the areas of erosions of different sizes were made by the repeated tracing of squares of different sizes drawn out on graph paper (Table 1). These areas were chosen as being similar to those of erosions on the macroradiographs. For each separate square 40 measurements were taken. The mean and the coefficient of variation were calculated; the standard deviation was expressed as a percentage of its associated mean. ${ }^{18}$ The test for the direct measurement accuracy for length was carried out in a similar manner. The 40 measurements taken for each length were subjected to the same statistical analysis described above for area measurements (Table 2).

During the $x$ ray procedure the wrist and hand were held in a stereotaxic unit to restrict movement. The effect of repositioning on repeat visits was assessed from the macroradiographs of five patients who had each completed four $x$ ray visits. For length

Table 1 Accuracy of direct area measurements

\begin{tabular}{lll}
\hline Area $(\mathrm{mm})$ & Mean area & $C V^{*}$ \\
\hline 25 & $25 \cdot 2$ & $4 \cdot 6$ \\
100 & $100 \cdot 5$ & $2 \cdot 3$ \\
225 & $225 \cdot 7$ & $1 \cdot 8$ \\
400 & $395 \cdot 9$ & $1 \cdot 3$ \\
625 & 621.8 & $1 \cdot 3$ \\
\hline
\end{tabular}

${ }^{*} \mathrm{CV}=$ coefficient of variation.

Table 2 Accuracy of direct linear measurements

\begin{tabular}{lcl}
\hline Length $(\mathrm{mm})$ & Mean length & $C V^{*}$ \\
\hline 2 & 1.9 & $9 \cdot 8$ \\
4 & 3.0 & $7 \cdot 1$ \\
6 & 5.9 & 3.5 \\
8 & 7.9 & 1.8 \\
10 & 10.0 & $1 \cdot 3$ \\
\hline
\end{tabular}

measurements the proximodistal width of the scaphoid and the mediolateral width of the second middle phalanx were measured. For area the outline $\underset{\vec{D}}{\vec{D}}$ of the pisiform and the hook of the hamate were chosen. These measurements were carried out twice on both right and left hands. To compare the changes in the different structures measured due to alteration in repositioning the hand the data were summarised as a coefficient of variation (Tables $3 \mathrm{c}$ and 4).

The error involved in the repeatability of measurements, including the initial identification of $\vec{\omega}$ erosions and the defining of their boundaries using wax pencil, was determined. The macroradiographs $\bar{?}$ of one patient with moderately advanced rheuma- is toid arthritis were cleaned of all previous wax pencil or marks. The stereopair macroradiographs were then examined under the stereoscope and the erosions 6

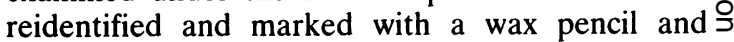
measured for area. The procedure was repeated five $\vec{\overrightarrow{ }}$ times over a two week period. The coefficient of variation was used to compare the error between the different regions of the wrist and hand (Table 5). This procedure was not carried out for the length $\%$ measurements required in assessing joint space

Table 3 Repositioning error assessment for area measurement expressed as $C V$

\begin{tabular}{|c|c|c|c|c|c|c|}
\hline & \multicolumn{6}{|c|}{ Patient } \\
\hline & $I$ & 2 & 3 & 4 & 5 & Mean \\
\hline \multicolumn{7}{|l|}{ Left } \\
\hline Pisiform & $6 \cdot 5$ & $6 \cdot 5$ & $2 \cdot 7$ & $2 \cdot 8$ & $8 \cdot 9$ & $5 \cdot 5$ \\
\hline Hook of hamate & $6 \cdot 1$ & $4 \cdot 7$ & $6 \cdot 3$ & $4 \cdot 8$ & $6 \cdot 1$ & $5 \cdot 6$ \\
\hline Mean & $6 \cdot 3$ & $5 \cdot 6$ & $4 \cdot 5$ & $3 \cdot 8$ & $7 \cdot 5$ & $5 \cdot 5$ \\
\hline \multicolumn{7}{|l|}{ Right } \\
\hline Pisiform & $6 \cdot 9$ & $11 \cdot 5$ & $5 \cdot 8$ & $3 \cdot 4$ & $5 \cdot 5$ & $6 \cdot 6$ \\
\hline Hook of hamate & $8 \cdot 00$ & $13 \cdot 8$ & $5 \cdot 8$ & $5 \cdot 7$ & $7 \cdot 3$ & $8 \cdot 1$ \\
\hline Mean & $7 \cdot 5$ & $12 \cdot 7$ & $5 \cdot 6$ & $4 \cdot 5$ & $6 \cdot 4$ & $7 \cdot 3$ \\
\hline Patient average $\mathrm{CV}$ & $6 \cdot 9$ & $9 \cdot 2$ & $5 \cdot 1$ & $4 \cdot 1$ & $7 \cdot 0$ & $6 \cdot 5$ \\
\hline
\end{tabular}

Table 4 Repositioning error assessment for length measurement expressed as $\mathrm{CV}$

\begin{tabular}{|c|c|c|c|c|c|c|}
\hline & \multicolumn{6}{|c|}{ Patient } \\
\hline & 1 & 2 & 3 & 4 & 5 & Mean \\
\hline \multicolumn{7}{|l|}{ Left } \\
\hline Scaphoid & $3 \cdot 0$ & $3 \cdot 6$ & $1 \cdot 7$ & $3 \cdot 2$ & $2 \cdot 8$ & $2 \cdot 9$ \\
\hline Second phalanx & 0.9 & $2 \cdot 1$ & $1 \cdot 2$ & 1.7 & $10 \cdot 3$ & $3 \cdot 2$ \\
\hline \multicolumn{7}{|l|}{ Right } \\
\hline Scaphoid & $1 \cdot 7$ & $6 \cdot 5$ & $7 \cdot 2$ & $5 \cdot 1$ & $3 \cdot 0$ & $4 \cdot 7$ \\
\hline Second phalanx & 3.7 & 0.7 & $1 \cdot 1$ & $3 \cdot 6$ & $11 \cdot 1$ & $4 \cdot 0$ \\
\hline Patient average $\mathrm{CV}$ & $2 \cdot 4$ & $3 \cdot 2$ & $2 \cdot 8$ & $3 \cdot 4$ & $6 \cdot 8$ & $3 \cdot 7$ \\
\hline
\end{tabular}


Table 5 Accuracy of the repeated identification of erosions (number) and their area measurements

\begin{tabular}{lcc}
\hline Region & $C V$ number & $C V$ area \\
\hline Wrist & 1.6 & $5 \cdot 2$ \\
MCP* & 9.6 & 21.4 \\
PIP* & 9.1 & $20 \cdot 2$ \\
DIP* & 14.0 & 23.0 \\
Mean & 4.8 & $7 \cdot 5$ \\
\hline
\end{tabular}

${ }^{*} \mathrm{MCP}=$ metacarpophalangeal; $\quad \mathrm{PIP}=$ proximal interphalangeal; DIP $=$ distal interphalangeal.

width as the margins of the latter were clearly defined in the macroradiographs.

To determine the magnitude of change in joint space width and erosion area resulting from disease progression the initial and six monthly follow up macroradiographs of five randomly chosen patients were examined. The following joint space widths were measured: between the carpal bones, the metacarpophalangeal (MCP), proximal interphalangeal (PIP), and distal interphalangeal (DIP) joints. Only erosions which did not amalgamate with adjacent erosions during enlargement were included. For each joint width and erosion area the mean and standard deviation for four visits and its coefficient of variation were calculated.

\section{Results}

The means and coefficients of variation for the direct measurement of area and length are given in Tables 1 and 2; although larger when small lengths or areas are measured, the coefficients are generally low. The means and coefficients of variation for changes in position of the wrist and hand on four successive $x$ ray visits are given in Tables 3 and 4 . For area measurements the range of the coefficient of variation for any one structure was from 2.7 to $13.8 \%$, and the range of variation in repositioning between patients was from $4 \cdot 1$ to $9 \cdot 2 \%$, with an average of $6.5 \%$ over the period of the study. For length measurements the range of coefficient of variation was from 0.7 to $11.1 \%$, and the range for repositioning variation between patients was from 2.4 to $6.8 \%$, with an average of $3.7 \%$ over the period of the study. These figures were independent of the size of the structure measured but were slightly greater in the right hand (length $4.0 \%$, area $7 \cdot 3 \%$ ) than the left (length $3 \cdot 2 \%$, area $5 \cdot 5 \%$ ).

The error associated with identification and repeatability of erosion measurement combined varied widely between the different regions of the wrist and hand. The carpus showed least variation followed by the PIP then the MCP joints, with the DIP joints showing the greatest. The average coefficient of variation for erosion identification (number) was $4 \cdot 8 \%$ and for area $7 \cdot 5 \%$.

Joint space loss in five patients over 18 months showed a mean patient coefficient of variation of $12.7 \%$ (range $8.9-19.5 \%$ ), and $90 \%$ of all joint spaces measured changed in size by between 3.4 and $33.3 \%$ over the four visits. Erosions changed in area by a mean patient coefficient of variation of $42 \%$ (range $7-154 \%$ ) (Fig. 1). 90\% of erosions studied altered in size by between 13 and $78 \%$ over the period of four visits.

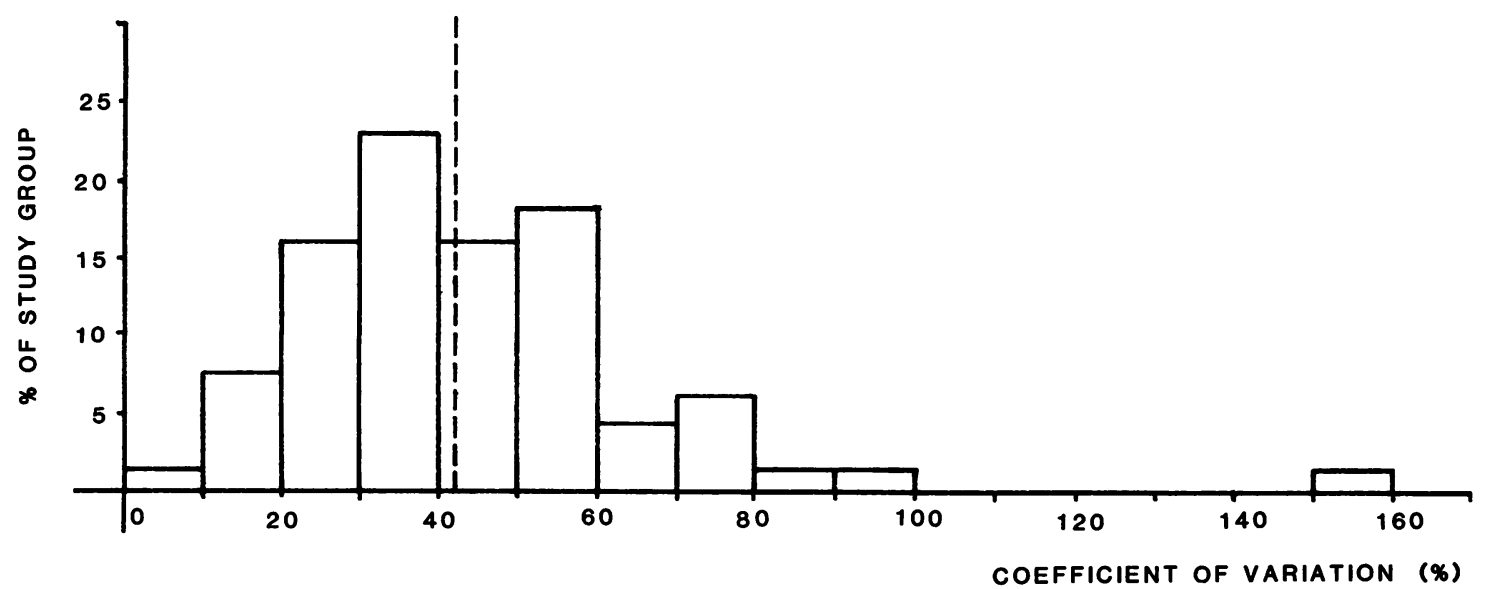

Fig. 1 Histogram showing the extent of the change in erosion size during the period of study, expressed as the coefficient of variation. The mean of $42 \%$ is indicated by the broken line. 


\section{Discussion}

Stereoscopic examination of the macroradiographs provides a three dimensional appreciation of bone and joint structure, enabling the observer to identify accurately the borders of the joint spaces and the presence and margin of bony erosions. The direct length and area measurements with the cursor and digitiser tablet showed greater variability in the measurement of small structures. Quantifying the dimension of structures recorded in the $\times 5$ magnification radiographs confers a greater mensural accuracy than can be achieved in measuring their actual size when visible in conventional radiographs. However, although the coefficient of variation of measurement was low for larger areas $(225,400 \mathrm{~mm})$, the error was larger than might have been expected relative to the small structures. A possible explanation for this is that when the cursor was traced around the larger areas wrist and arm movements were required as opposed to fine finger movements for the smaller areas. Further, in the macroradiographs tracing the margin of an erosion shadow inaccuracies could arise through the number of 'outline decisions' required during the procedure.

The different repositioning in the right and left hands for length and area measurements in the stereotaxic device was related to its design, which permits the left hand to be held with greater firmness than the right.

The repeatability of erosion identification and measurement (Table 5) showed that the coefficient of variation calculated for the number of erosions identified was on average $4.8 \%$ and for their area $7 \cdot 5 \%$. These means do not take into account the relative number of erosions that occurred in the different regions. The results showed the errors to be less in the wrist than in the joints of the hand. Variations in consistent identification of erosions were probably related to poor contrast range within the $x$ ray film either from under- or overexposure. Under these circumstances the lesion and its margins are less clearly defined. This effect was certainly more marked in the PIP and DIP joints, where the bones were thinner. In addition, a similar problem of identification occurred when osteoporosis was present. Here erosion margins became less distinct, notably in the PIP and DIP joints. A weighted measure of repeatability might be introduced to reduce the effect of the error at the different joints of the hand. However, retrospective reviewing of the series of four films from one patient was introduced to renove false positive and false negative erosion identification. Some features resembling erosions did not alter in size during the study period (false positives), while some erosions not marked at a given site on one visit were present $\frac{}{\omega}$. in the macroradiographs of the other visits and clearly visible on review (false negatives). The $\stackrel{\vec{F}}{\stackrel{*}{?}}$ extent of the change in area of erosions over the $\overline{0}$ study period was much greater than the variations 등 due to errors in repositioning the wrist and hand on $\frac{\bar{m}}{\vec{s}}$ successive $x$ ray visits, or to erosion identification $\mathbb{\mathbb { D }}$ and area measurement. The mean coefficient of variation of the erosion area over the 18 months was $42 \%$ (range $7-154 \%$ ) and of joint space was $12.7 \%$. (range $8 \cdot 9-19 \cdot 5 \%$ ), while that due to all errors was $\overrightarrow{\vec{\omega}}$ only $13.1 \%$ for area and $3.7 \%$ for length. These ${ }_{\Omega}^{\omega}$ errors correspond approximately to the fifth percentile level for the magnitude of erosion area and joint space changes.

The application of this measurement technique to the present group of patients being studied ${ }^{17}$ should $\underset{0}{\omega}$ provide an accurate account of the anatomical 0 distribution of erosions and joint space loss in the wrist and hand and the frequency of formation of $\bar{z}$ erosions in the different bones, together with a description of the relative rates of progression of the $\vec{\bullet}$ different radiographic features at different sites. Furthermore, by considering the rate of change in erosion size, the data could be used to provide an index of disease activity.

We wish to thank Dr R Grahame, Professor G Panayi, and Dr T $\frac{\text { Q }}{\mathrm{D}}$ Gibson for their cooperation in providing the patients for $x$ ray examination. This work is being generously supported by the $\overrightarrow{\bar{D}}$ Arthritis and Rheumatism Council and Ciba Geigy Pharmaceuticals.

\section{References}

1 Chasin A. Die Dimensionen der destruktiven Veränderungen in den Wirbelkörpern, die roentgenographisch bestimmt werden können. Fortschr Geb Rontgenstr 1928; 37: 529-35.

2 Bohmig R, Prevot R. Vergleichende Untersuchungen zur Pathologie und Rontgenologie der Wirbelsaule. Fortschr Geb? Rontgenstr 1931; 43: 541-75.

3 Borak J. Relationship between the clinical and roentgenological 3 findings in bone metastases. Surg Gynecol Obstet 1942; 75: 599-604.

4 Ardran G M. Bone destruction not demonstrable by radio- $D$ graphy. Br J Radiol 1951; 24: 107-9.

5 Goldman $\mathrm{H}$ M, Millsap J S, Brenman H S. Origin of registration of the architectural pattern, the lamina dura and the $\mathrm{N}$ alveolar crest in the dental radiograph. Oral Surg 1957; 10: $749-58$.

6 Bender I B, Seltzer S. Roentgenographic and direct observation of experimental lesions in bone. J Am Dent Assoc 1961; 62: 152-60.

7 Becks H, Grimm D H. Comparative roentgenographic ande histologic study of human mandibles. Am J Orthod Oral Surg 1945; 31: 383-406.

8 Ely $\mathrm{R}$ V, ed. Microfocal radiography. London, New York: Academic Press, 1980.

9 Hobdell $M \mathrm{H}$. The relationship between the function and structural organization of bone in the jaws of mammals. London University, 1970. (Thesis.)

10 Buckland-Wright J C. The structure and function of cat skull bones in relation to the transmission of biting forces. London University, 1975. (Thesis.) 
11 Buckland-Wright J C. Stereo-projection radiography in the study of the structural organisation of cat skull bones. J Anat 1980; 130: 487-98.

12 Buckland-Wright J C. Bone structure and the patterns of force transmission in the cat skull (Felis catus). J Morphol 1978; 155: $35-62$.

13 Buckland-Wright J C. Microfocal radiography in the quantitative assessment of experimentally induced inflammatory arthritis in guinea-pigs. $J$ Pathol 1981; 135: 127-45.

14 Buckland-Wright J C. Qualitative and quantitative assessment of tissue organization in normal and discased organs. In: Ely
R V, ed. Microfocal radiography. London. New York: Academic Press, 1980: 147-95.

15 Buckland-Wright J C. $X$-ray assessment of activity in rheumatoid disease. Br J Rheumatol 1983; 22: 3-10.

16 Buckland-Wright $\mathrm{J} \mathrm{C}$. Advances in the radiological assessment of rheumatoid arthritis. BrJ Rheumatol 1983; 22 (suppl): 34-43.

17 Buckland-Wright J C. Microfocal radiographic examination of erosions in the wrist and hand of patients with rheumatoid arthritis. Ann Rheum Dis 1984; 43: 160-71.

18 Strike P W. Medical laboratory statistics. Bristol, London: Wright, PSG, 1981. 